The Rule OF LAW: Beyond CONTESTEDNESS

PAul Burgess 


\section{The Rule OF LAw: Beyond CONTESTEDNESS}

\section{PART I: INTRODUCTION}

In this paper I propose a novel - theory agnostic - elemental approach to the initial identification of Rule of Law non-compliance. I argue that, by identifying common aims that undergird the most frequently cited conceptions of the Rule of Law, it is possible to look beyond the contestedness that is all too apparent in debates regarding the Rule of Law's conceptual content. In taking this approach, it is possible to identify two elements that reflect fundamental needs that are commonly held across all canonical conceptions.

The Rule of Law is undoubtedly a contested concept. ${ }^{1}$ The conceptions themselves have been described as not only "often conflicting and not infrequently rather confused". ${ }^{2}$ The Rule of Law's contested nature is problematic for many reasons; not least of which are the potential analytical unclarity, confusion and loss of pragmatic benefit that follows the contest of such a widely cited concept. To look beyond the contestedness, it is necessary to look beyond the widely cited Rule of Law desiderata; to do this, it is argued, it is necessary to identify the fundamental needs each thinker intended to satisfy in formulating those desiderata. Through identifying the fundamental need that was being addressed, and by considering each of the most widely cited Rule of Law ideas, the identification of commonalities in the fundamental need is possible. This allows the distillation of two Rule of Law elements: Comprehension and Procedural Pellucidity. (The elements' operation is not exclusive even though they exist, and overlap, on a spectrum between processes and outcomes: Procedural Pellucidity — at the processes end of the spectrum—relates to norm-makers and appliers; and Comprehension-at the outcomes end-relates to norm followers.) $)^{3}$ The elements: are derived from within the DNA of canonical Rule of Law conceptions; can be identified across canonical conceptions; and, reflect the fundamental needs communicated by each canonical author. In consequence of the way that the elements are derived, satisfaction of both elements is necessary for

\footnotetext{
${ }^{1}$ For a detailed summary of the debate, see Jeremy Waldron, 'Is the Rule of Law an Essentially Contested Concept (in Florida)?' (2002) 21 Law and Philosophy 137.

2 Andrei Marmor, 'The Rule of Law and Its Limits' (2004) 23 Law and Philosophy 1, 1.

${ }^{3}$ I explore the nature of the overlap in section 4.2 .
} 
Rule of Law compliance regardless of which canonical conception is preferred or considered. Accordingly, should either be absent in the normative commands of a sovereign power or in relation to the operation of a legal system more generally, Rule of Law compliance cannot follow. In these terms, the elements' formulation and application enables the initial and immediate identification of non-compliance with any canonical idea of the Rule of Law. Why is this important? In circumstances where, despite the debate and the lack of any agreed definition of the concept, apex courts across the Common Law world frequently reference the Rule of Law's importance, ${ }^{4}$ and as the level of contestedness seems capable of hindering research and the concept's theoretical application, ${ }^{5}$ bringing clarity to the debate together with ease of application of the concept is vital. The elements derived in this paper address this problem by providing a new way to evaluate Rule of Law compliance through identification - at an early stage and in a theory-agnostic way-of Rule of Law non-compliance that avoids becoming bogged in the quagmire of contestedness that is apparent in the literature.

In debates regarding the Rule of Law's conceptual content it could be seen as being generally agreed that the concept, whatever else it may be, relates to the imposition of a normative constraint upon the exercise of power. But this-overly broad generalisation - could be seen as being practically useless for assessing compliance with the concept. Yet, when the concept's canons' more specific definitions are considered, the contest regarding the concept's content becomes intense. This results in various contests regarding both the concept's application and operation and its content that relate to, inter alia, whether the Rule of Law should be applied in an international sphere ${ }^{6}$ or whether the Rule of Law should be construed in formal

\footnotetext{
${ }^{4}$ Regina $v$ Secretary of State for the Home Department, Ex Parte Pierson (1998) AC 539 575. Planned Parenthood of Se Pennsylvania v Casey (1992) 505 US 833. (O’Connor, Kennedy \& Souter, JJ.) (Opinion of the Court). See also Bush v Gore (2000) 531 US 98, 128-129. Regarding the US Supreme Court's interest and focus on the Rule of Law, see Paul Burgess, “[The Rule of Law]” in the US Supreme Court: The Elephant in the Court Room?' (2016) 8 Hague Journal on the Rule of Law 421.

${ }^{5}$ Adriaan Bedner, 'An Elementary Approach to the Rule of Law' (2010) 2 Hague Journal on the Rule of Law 48, 49; Ryan E Carlin and Rodolfo Sarsfield, 'Rethinking the Rule of Law: Concepts, Measures, and Theory' (2012) 33 Justice System Journal 125, 125-130.

${ }^{6}$ Simon Chesterman, 'An International Rule of Law?' (2008) 56 American Journal of Comparative Law 331; Jeremy Waldron, 'Are Sovereigns Entitled to the Benefit of the International Rule of Law?' (2011) 22 European Journal of International Law 315.
} 
or substantive terms. ${ }^{7}$ (Formal terms relate to the processes of enacting a law; ${ }^{8}$ substantive terms relate to other considerations including, for example, democracy, liberty and freedom.) There are also fine grained debates regarding the concept's content as some suggest a Rule of Law conceptual core exists, ${ }^{9}$ others consider it is an essentially contested ${ }^{10}$ or, at least, deeply contested concept. ${ }^{11}$ The formulation of the idea itself is frequently illustrated at the most basic level in the various 'laundry lists' of desiderata. Whilst this practice has become popular, ${ }^{12}$ a contest remains as to which list (and criticisms of the same) to adopt. Whilst the authors frequently included as part of the debate have been described as a “ “ $[\mathrm{w}]$ ho’s who' of Western political thought"13_ and include figures like Aristotle, Hobbes, Locke, Dicey, Hayek, Fuller, Dworkin, Raz, Radin and Waldron-the formulations posed by, or attributed to, these thinkers often conflict and overlap. To assess Rule of Law compliance, one is required to either have recourse to each and every canonical conception; select aspects of one of various ideas; or create a novel Rule of Law conception. However, each method poses a problem. Creating a purpose built Rule of Law conception has the advantage of precisely delimiting the boundaries of the conception, but this is labour intensive and impractical for most projects. Hybrid laundry lists of (relatively) uncontroversial desiderata avoid this impracticality, ${ }^{14}$ but they may be criticised for cherry-picking desiderata tailored to support a desired conclusion. For

\footnotetext{
7 Paul Craig, 'Formal and Substantive Conceptions of the Rule of Raw an Analytical Framework' [1997] Public Law 467. See also Brian Z Tamanaha, On the Rule of Law History, Politics, Theory (Cambridge University Press 2004) 91.

${ }^{8}$ See, for example, Raz's desiderata: Joseph Raz. Joseph Raz, The Authority of Law: Essays on Law and Morality (2nd edn, Oxford University Press 2009) 214-219.

${ }^{9}$ See for example, Brian Z Tamanaha, 'The History and Elements of the Rule of Law' [2012] Singapore Journal of Legal Studies 232. See also, Lisa M Austin and Dennis Klimchuk (eds), Private Law and the Rule of Law (Oxford University Press 2014) 1. Further examples regarding the centrality of arbitrariness and the exercise of power can be seen in Krygier's work: Martin Krygier, 'The Rule of Law: Legality, Teleology and Sociology' in Gianluigi Palombella and Neil Walker (eds), Relocating the Rule of Law (Hart 2009); Martin Krygier, 'Tempering Power' in Maurice Adams, Ernst Hirsch Ballin and Anne Meuwese (eds), Bridging Idealism and Realism Constitutionalism and Rule of Law (Social Science Research Network 2016). (Forthcoming.) 10 Waldron, 'Is the Rule of Law an Essentially Contested Concept (in Florida)?' (n 1); Richard H Fallon Jr, “The Rule of Law” as a Concept in Constitutional Discourse' (1997) 97 Columbia Law Review 1, 7. ${ }^{11}$ Margaret Jane Radin, 'Reconsidering the Rule of Law' (1989) 69 Boston University Law Review $781,781$. 12 A non-exclusive list would include: Raz (n 8) 214-219; Lon L Fuller, The Morality of Law (Yale University Press 1964) 46-94; Jeremy Waldron, 'The Concept and the Rule of Law' (2008) 43 Georgia Law Review 1. ${ }^{13}$ Jørgen Møller and Svend-Erik Skaaning, The Rule of Law: Definitions, Measures, Patterns and Causes (Palgrave Macmillan 2014) 2.

${ }^{14}$ See Chesterman (n 6) 343; Waldron, 'Are Sovereigns Entitled to the Benefit of the International Rule of Law?' (n 6) 316. See also Stéphane Beaulac, 'An Inquiry into the International Rule of Law' (2007) 14 (2007) European University Institute Working Papers, MWP 1, 8-10.
} 
these reasons, and as there is no agreement regarding the correctness of any single theory, none of these approaches facilitate a practical solution beyond immediate criticism. In other words, the contestedness means there is no practical and pragmatic way to immediately determine if an action contravenes the Rule of Law in all of its most widely cited conceptions or in terms that is not open to immediate criticism. By being conceived at a greater level of abstraction, the Rule of Law elements I identify exist beyond the Rule of Law desiderata and the contest regarding these specific aspects of the ideas. In taking this approach - and by focusing on what is common in the goals, and not just the canonical conceptions' desiderata or the similarities in those desiderata- the problems that stem from the concept's contestedness can be avoided and a way to identify non-complinace becomes apparent.

My investigation is heuristic, ${ }^{15}$ with an intent to distill the ends inhering in canonical thinkers' conceptions and not on the intrinsic function the concept of the Rule of Law (as a concept) fulfils ${ }^{16}$. I do not claim to identify what the Rule of Law $i s$; as, in consequence of the methodology I adopt, that would necessarily require the canonical conceptions to be accurate statements of what the Rule of Law is. In this respect, whilst describing the Rule of Law in terms of its elements is not new, ${ }^{17}$ my approach is novel. I argue two elements can be distilled from the common needs that undergird the most frequently cited conceptions of the Rule of Law (what I will call 'canonical' conceptions.) The elements can be defined in these terms:

Comprehension: $\quad$ That an individual be able to comprehend the nature, con-
tent and operation of the rules to which he or she is subject.

Procedural Pellucidity: The creation and application of any rules must be in terms capable of being clear and obvious to all concerned.

\footnotetext{
${ }^{15}$ My methodology has much in common Bedner's: Bedner (n 5). However, the meaning of 'element' differs. (Bedner's meaning is in terms of Rule of Law 'basics' or 'principles'.)

${ }^{16}$ It is in this respect that the methodology I adopt differs from previously suggested teleological ideas of the Rule of Law. See, for example, Krygier, (n 9). and Martin Krygier, 'Law as Tradition' (1986) 5 Law and Philosophy 237.

${ }^{17}$ See, for example, Tamanaha (n 9) 232; Bedner (n 5); Christopher May, The Rule of Law: The Common Sense of Global Politics (Edward Elgar Publishing 2014) 33.
} 
The elements provide a clear conceptual lens through which to assess Rule of Law non-compliance in a way that avoids the concept's contestedness. The failure to satisfy either or both elements is sufficient-but not necessary-for Rule of Law noncompliance to result. As the failure to satisfy the elements is not a necessary condition of noncompliance, this failure is not the only way Rule of Law noncompliance may result. The elements are, however, necessary — but not sufficient—for Rule of Law compliance. ${ }^{18}$ By virtue of their necessary location in any Rule of Law compliant scheme (regardless of the canonical conception preferred), the elements provide - in relation to the problems referred to above-one way to pragmatically and practically — and without immediate criticism — assess Rule of Law non-compliance. The project could be described as theoretical Esperanto: ${ }^{19}$ bringing together the existing theoretical languages of the various canonical Rule of Law ideas and translating their meaning into a new-derived - theoretical language capable of achieving the same ends as the original language in terms that remain agreeable to all. This process does not determine ultimate compliance with the Rule of Law nor does it outline the only instances of non-compliance-as other factors may determine or impact these outcomes - it merely facilitates immediate identification of non-compliance. This small step is useful in addressing the problems outlined above.

To frame the solution posed in this paper, I first, in Part II, delineate the boundaries of the study before outlining my methodology. In Part III, I evidence the distillation of the elements from the canonical conceptions. In Part IV, I preempt some criticisms of the proposed scheme before concluding my argument in Part V.

\section{PART II: The Rule of LAW}

But there is no real consensus on the form of Rule of Law contest. The ever growing number of conceptions result in varying levels and forms of contestedness across the Rule of Law ideas. The variety of ideas has been put in these terms: “...

\footnotetext{
${ }^{18}$ I thank the anonymous reviewer for highlighting the importance of clearly stating the full necessary and sufficient sides of this equation.

${ }^{19}$ I am grateful to Dan Carr of the University of Edinburgh for suggesting a term that so clearly illustrates my conceptual processes.
} 
the rule of law may not be a single concept at all; rather, it may be more accurate to understand the ideal of the rule of law as a set of ideals connected more by family resemblance than by a unifying conceptual structure.”20 What is, nevertheless, clear is that there appears to be an ongoing contest between the various Rule of Law ideas; this extends across both time and geography. ${ }^{21}$ This has led suggestions that the Rule of Law is deeply contested ${ }^{22}$ or essentially contested (in the Galliean sense). ${ }^{23}$ Whilst Jeremy Waldron's 2002 paper is most frequently cited as authority for this position, ${ }^{24}$ he makes no mention of essential contestedness his recently authored 'Rule of Law' entry in the Stanford Encyclopedia of Philosophy. ${ }^{25}$ In this sense, the essential contestability of the concept is not settled and could itself be contested. In this paper, I do not seek to challenge the question of essential contestability and the Rule of Law, nor do I need to. The distillation of the elements derives from beyond the contestedness - whatever form it may take - to identify a commonality in the canonical authors' apparent fundamental need. On this approach, the conceptions themselves are not linked and the contest between them-at the level of the conceptions' desiderata-is not resolved.

\subsection{Formally framing the discussion}

I adopt only a formal consideration of the Rule of Law. In explaining why this approach is adopted, it is useful to consider F. A. Hayek's definition of the Rule of Law:

[S]tripped of all technicalities this means that government in all its actions is bound by rules fixed and announced beforehand-rules which make it possible to foresee with fair certainty how the authority will use its coercive powers in

\footnotetext{
${ }^{20}$ Lawrence B Solum, 'Equity and the Rule of Law' (1994) 36 Nomos 120, 121.

${ }^{21}$ Chesterman (n 6) 340.

${ }^{22}$ Radin (n 11) 781.

${ }^{23}$ Waldron, 'Is the Rule of Law an Essentially Contested Concept (in Florida)?’ (n 1); Fallon (n 10$) 7$.

${ }^{24}$ Waldron, 'Is the Rule of Law an Essentially Contested Concept (in Florida)?' (n 1); Tamanaha (n 9) 232; Møller and Skaaning (n 13) 2.

${ }^{25}$ Jeremy Waldron, 'The Rule of Law' in Edward N Zalta (ed), The Stanford Encyclopedia of Philosophy (Fall 2016, 2016) <http://plato.stanford.edu/archives/fall2016/entries/rule-of-law/> accessed 24 September 2016.
} 
given circumstances and to plan one's individual affairs on the basis of this knowledge. ${ }^{26}$

Hayek's statement has been described as 'one of the most powerful formulations of the ideal of the rule of law'. ${ }^{27}$ It is difficult to conceive of a more succinct yet general exposition. Yet, this_-formal (or ‘thin')—idea could be criticised for excluding any substantive ideas. This criticism is echoed when the formal Rule of Law is criticized for failing to prevent the enactment of evil laws. This arises in relation to the Hart-Fuller debate and, in particular, when interpretations of Fuller's viewthat immoral laws should not have legal force ${ }^{28}$ — are considered. However, the use of a formal approach to Rule of Law consideration is not without merit ${ }^{29}$ as it avoids both the contamination of an examination by substantive considerations ${ }^{30}$ and the muddying of conclusions by the inclusion of additional factors under the Rule of Law umbrella term (as occurs in substantive conceptions). ${ }^{31}$ Accordingly, in circumstances where the goal is to clearly identify the elements of the Rule of Law, it makes sense to start from a thin base. Further, as formal ideas of the concept provide a foundation for any substantive conception and as the elements I propose are necessary (but not sufficient) components of the formal conception, should the elements not be satisfied in its formal conception, they could not be satisfied in or support any substantive conception. Putting this another way, failure to satisfy the elements results in a failure to satisfy the Rule of Law regardless of whether conceived in formal or substantive terms. For these reasons, a formal conception is enough to address the problem - that, as a result of the contestedness of the concept, there is no practical way to assess Rule of Law non-compliance-raised in this paper.

\subsection{Rule of Law Elements}

In this section, I suggest it is possible to infer from a canonical author's choice of desiderata, and the author's situation more broadly, the fundamental need

\footnotetext{
${ }^{26}$ Friedrich A von Hayek, The Road to Serfdom (Bruce Caldwell ed, University of Chicago Press 2007) 112.

${ }^{27} \operatorname{Raz}(\mathrm{n} 8) 210$.

${ }_{28}$ Waldron, 'The Concept and the Rule of Law' (n 12) 17.

${ }^{29}$ Charles Sampford, 'Reconceiving The Rule of Law for a Globalizing World' in Spencer Zifcak (ed), Globalisation and the Rule of Law (Routledge 2005) 19.

30 See Chesterman (n 6) 360.

${ }^{31}$ See Craig (n 7) 469. (Summarizing the argument made by Raz (n 8).) In relation to the exclusion of democracy and human rights from Rule of Law ideas, see Tamanaha (n 9) 233-236.
} 
that the Rule of Law theory was aimed at addressing. I describe the inference necessary to make the move from canonical Rule of Law laundry lists of desiderata to the elements of Comprehension and Procedural Pellucidity. (The distillation of the elements will take place in the next part.)

Tool analogies are popular in the Rule of Law debate. After distinguishing one, I will use two to illustrate my point. Joseph Raz, famously, suggests a knife is only a knife if it has some ability to perform its necessary function: for a knife, an ability to cut. ${ }^{32}$ Raz considers the various virtues that may exist in relation to the satisfaction of a particular end. As the present enquiry considers there may be a number of potential ends, Raz's analogy can only precisely relate if an idea is read into his proposition that there could be a number of other tools able to achieve the same ends: for Raz, cutting. However, in arguing that Margaret Radin's portrayal of Fuller's work as an instrumental conception of the Rule of Law may be mistaken, Jeremy Waldron provides a tool related analogy that does assist. As it is referred to throughout this paper it is worth extracting in full:

If one wanted to cut down a large tree with an axe, one would have to be sure that the axe was heavy and the head rigid. Heaviness and rigidity in an axe are desiderata for doing things with axes, particularly the things that axes are normally used to do. It does not follow, however, that the heaviness and rigidity of one's tools are general desiderata for cutting down trees. For one might opt to use a two-handed saw - and then maybe lightness and flexibility would be one's instrumental virtues. If the two-handed saw is a better tool than the axe for chopping down some tree... then the fact that certain features are desiderata in a good axe does not amount to a general instrumental justification for those features. ${ }^{33}$

Waldron's suggests that ends alone do not justify Rule of Law theories and desiderata alone cannot provide definitive and general justification for the features. Two questions posed by Waldron reflect this: which tool is most efficacious for the goal in mind? and, given the selection of a certain kind of tool, what attributes of

\footnotetext{
${ }^{32}$ Raz (n 8) 225-226. See also, Paul Burgess, 'Neglecting the History of the Rule of Law: (Unintended) Conceptual Eugenics' (forthcoming) Hague Journal on the Rule of Law.

33 Jeremy Waldron, 'Why Law - Efficacy, Freedom, or Fidelity?' (1994) 13 Law and Philosophy 259, 261-262.
} 
that tool best serve the goal? ${ }^{34}$ These questions do not preclude the inquiry that I propose: that the purpose and intent behind the choice of tool can be inferred from the tool's attributes and the context of the situation more generally. Waldron's questions illustrate the structure of any theorist's formulation of a Rule of Law theory would differ based on that theorist's appreciation of the problem. ${ }^{35}$ That appreciation would, in turn, impact the selection of the theory scheme (as a tool) and the associated Rule of Law desiderata (as the tool's instrumental virtues). It would follow, where the Rule of Law is contested and a variety of laundry lists of desiderata exist, without knowing any theorist's precise conception of the problem a direct comparison (of tools or tools' instrumental values) would render the examination subject to the same problem identified by Waldron. In effect, comparing an axe with a saw, or an axe with an axe, or the individual characteristics of both axes and saws in circumstances where the individual theorist's goal has not been identified in toto. This reflects, in a basic sense, the problems in the Rule of Law's contestedness. These problems can, however, be avoided by focusing on what is common in the goals - and not just the desiderata or similarities in the desiderata - as each theorist's solution to a particular problem. Together, the abstraction and commonality place any distilled element beyond the concept's contestedness. By taking this approach, the problems can be avoided.

To say something more about my rationale, expanding the metaphor is useful. Theodore Levitt characterises customers' attendance at a hardware store seeking to purchase a drill bit in these terms: 'People don't want to buy a quarter-inch drill. They want a quarter-inch hole' ${ }^{36}$ This sentiment expresses a customer's need behind the need. Let us call this the Fundamental Need. Here I use 'fundamental' as relating to a necessary base or a core or, alternatively, relating to central importance. ${ }^{37}$ The use of the definitive 'the Fundamental Need' needs explanation. It is used despite, as will become apparent below, there exists potential to abstract further. (I explore this further in Part IV in the section entitled Why not abstract further?) It could be

\footnotetext{
34 ibid 262. See also Raz (n 8) 225-226.

${ }^{35}$ My perspective agrees with Waldron's suggestion that the Rule of Law is a 'solution-concept': Waldron, 'Is the Rule of Law an Essentially Contested Concept (in Florida)?' (n 1) 158.

${ }_{36}$ Clayton M Christensen, Scott Cook and Taddy Hall, 'Marketing Malpractice: The Cause and the Cure' (2005) 83 Harvard Business Review 74, 76.

37 'Fundamental - Definition of Fundamental in English | Oxford Dictionaries' (Oxford Dictionaries |

English) <https://en.oxforddictionaries.com/definition/fundamental> accessed 23 September 2016.
} 
argued that abandoning 'Fundamental' or avoidance of the definitive 'the Fundamental Need' may be more appropriate. This may, however, increase ambiguity as it would not be clear which need is being referred to. Accordingly, for conceptual clarity, and whilst the potential for further abstraction is recognised, 'the Fundamental Need' or 'Fundamental Need' is used here to refer to that which is identifiable as the level of abstracted need capable of being held in common across conceptions. This represents, in effect, the conceptions' conceptual sweet spot. It represents the point at which it is argued maximum practical and pragmatic benefit is obtained.

Whilst Levitt's business/marketing concept is far removed from legal theory, it can be directly applied to the task at hand. Statements of commonality in canonical desiderata merely express a potential solution to an initial need (but not the Fundamental Need.) They reflect a way to solve a problem and not an expression of the problem itself. This will, therefore, not provide a useful comparison as the desiderata alone will amount to no more than the identification of a commonality of functional or instrumental approach or process. Bedner's suggestion that it will be impossible to find a definition pleasing to all as any common ground for the ideas of the Rule of Law is thin ${ }^{38}$ is undoubtedly true unless a mere aesthetic of commonality is sought; for example, through basic similarities like the preponderance of calls for 'predictability'. However, exposing a common background purpose as a Fundamental Need would be meaningful. This would allow superficially similar surface expressions to be disambiguated and different surface expressions could be separately aggregated. Identification of a common Fundamental Need in canonical Rule of Law conceptions would represent an element—common to all ideas — of the Rule of Law that exists beyond the concept's contestation.

The common elements - that reflect the Fundamental Need — can be identified through the inference of intent or purpose: the common sharpness of both an axe and saw, when combined with the general nature and possible applications of those tools, suggests the goal is cutting; or, more specifically, cutting wood. From two individuals' selection of these two different tools, an open inference is that they

\footnotetext{
${ }^{38}$ Bedner (n 5) 53.
} 
both wish to cut wood. This is the - commonly held-Fundamental Need (as expressed through their individual tool selection.) Rule of Law elements can be identified in the same way. By considering a canonical author's formulation of a Rule of Law conception, the end to which the conception is directed can be inferred. This represents that thinker's Fundamental Need. Commonality across the Fundamental Needs of each canonical author provides the basis for the identification of the elements of the Rule of Law. As already noted, I do not intend to suggest that the Fundamental Need represents the most basic, or absolute, need that can be inferred from the conceptions contained in the Rule of Law canons. Cutting wood is not the only need that may be inferred from the tool's selection; a more abstract need would be to make firewood or to generate heat (from burning the cut wood). In taking this further abstracted step any commonality of purpose may, however, be lost. ${ }^{39}$ With commonality as the key ingredient in the Fundamental Need, the Rule of Law elements only_and specifically_reflect the commonly held Fundamental Need. By virtue of the elements being derived in this way, the elements - as a reflection of the Fundamental Need-are necessary for Rule of Law compliance across all Rule of Law canonical conceptions.

In taking a small step back, a basic question remains. How can we identify the Fundamental Need? When taken with theorists' stated goals, Rule of Law desiderata will inform the Fundamental Need. Rule of Law desiderata are useful as signposts of the theorists' intent; eschewing the relevance of these would be to throw the baby out with the bathwater as they are an embodiment of the theorists' solution to a problem and are, therefore, suggestive of the ultimate goal: the selection of an axe or saw (that each have sharpness as a characteristic) rather than a hammer (with dullness as a characteristic) suggests the goal is cutting rather than striking. However, it is only in considering a tool's characteristics in conjunction with the general nature of its circumstantial uses that the purpose-of cutting wood in this example - can be inferred. Accordingly, holistic consideration of canonical theories and desiderata will be apposite.

To avoid simply re-stating the broad rationale for the existence of the Rule of Law, and to provide some analytical benefit, the Fundamental Need must be a

\footnotetext{
${ }^{39}$ I consider the question of additional abstraction in 4.3 Why not Abstract Further? page 24 below.
} 
more specific ideal than the mere avoidance of arbitrary power or the limitation of government interference. Whilst I argue the two elements identified in the following part express the Fundamental Need, I do not suggest this is the only way in which this may be conceived; again, I am not suggesting the only purpose to be inferred from an axe or tool's sharpness is cutting wood. Whilst I will return to this point later, it suffices to say simply that cutting wood $i s$ an inference that can be made and, crucially, it is one that is common across the considered uses. For the validity of my argument, any further claim to exclusivity of purpose is unnecessary.

\section{PART III: Distilling the Elements}

In this part, I survey canonical conceptions of the Rule of Law to identify the elements defined in the opening pages of this paper: Comprehension and Procedural Pellucidity. Simply listing the canonical Rule of Law conceptions in attempting to distill the elements would be uninteresting and unhelpful. Accordingly, I propose each element and offer evidence for that element through recourse to the relevant canonical conceptions.

\subsection{Comprehension as an Element of the Rule of Law}

Comprehension $^{40}$ as an element of the Rule of Law requires that an individual be able to comprehend the nature, content and operation of the rules to which he or she is subject. Two aspects are encompassed in this formulation: that an individual must, first, receive and, second, process rules as part of an endeavor shared with another individual or entity. This reflects the two components of the dictionary definition: first, the ability to understand something ${ }^{41}$ or the faculty of grasping with the mind and the capacity to understand fully; ${ }^{42}$ and, second, the capability of including or inclusion. ${ }^{43}$ By offering general communication as an analogy before going on to examine various canonical conceptions, I evidence the way in which Comprehension is an element of the Rule of Law.

\footnotetext{
${ }^{40}$ Hereinafter "Comprehension" (with a capital 'C') refers to the element of the Rule of Law.

41 'Comprehension - Definition of Comprehension in English | Oxford Dictionaries' (Oxford Dictionaries | English) <https://en.oxforddictionaries.com/definition/comprehension> accessed 23 September 2016. ${ }_{42}$ 'Definition of "Comprehension”" (Merriam-Webster Online) < http://www.merriam-webster.com/dictionary/comprehension> accessed 23 September 2016.

43 ibid; 'Comprehension - Definition of Comprehension in English | Oxford Dictionaries' (n 41).
} 
In relation to general communication, comprehension has an obvious synonymy with canonical conceptions of the Rule of Law and their associated Rule of Law desiderata. Communicating through writing and speech includes fundamental prerequisites to understanding and therefore comprehension. For example, parties must adhere to the same rules. This includes the adoption and acceptance of common meanings of words and phrases within the chosen language and the mutual agreement to communicate in the same language (or at least in a way that both parties know can be understood by the other). Furthermore, parties must know in advance that each will continue to conform to these rules. In effect, there must be a practical ability to understand the form of the communication. There will not, for example, be actual communication in the broad sense, never mind comprehension, on the expression of a sentiment out of the earshot of the other party or if it follows a structure that makes no grammatical sense. These final categories are vital, as adherence to all of the other requirements would not, otherwise, facilitate comprehension. This suggests comprehension generally requires more than the exchange of propositions and the processing of an external input. It requires that there be a level of understanding or appreciation of what and how information is being, and will be, communicated. It also requires internal processing of a proposition through adherence to a set of commonly known and understood norms of conduct that assist the internal act of processing, and the formation and structuring of the appropriate outputs.

Comprehension, as a Rule of Law element, reflects these internal and external aspects. Both must be satisfied to facilitate Comprehension. The internal aspect - which I outline in more detail shortly — relates to an individual's ability to understand the nature, content and operation of the rules to which he or she is subject. The external aspect relates to the way in which the party receives or becomes aware 
of various norms. These can be simply stated by listing some of the obvious expressions of relevant desiderata that include calls for clarity, ${ }^{44}$ consistency or congruence, ${ }^{45}$ freedom from contradiction, ${ }^{46}$ or communication/promulgation. ${ }^{47}$ These relate to facets of norm formation external to an individual's control; in other words, they relate to the creation and packaging of a norm before it is received by the individual.

Comprehension as the Fundamental Need behind these requirements provides a realistic expression of the purpose common in each of these canonical statements. A party's (internal) awareness of rules facilitates Comprehension of both the existence and application of the rule as well as the rule's relevance to the party. The fact that there must be rules and they must be general appears to be the least controversial of all Rule of Law desiderata. Fuller includes this as his first requirement; ${ }^{48}$ it is also a requisite in formulations by and Raz, ${ }^{49}$ Solum, ${ }^{50}$ and Hayek. ${ }^{51}$ A requirement for rules by way of written, albeit potentially changeable, laws expressed in general terms has also been stated as being fundamental to the classical conceptions of the Rule of Law. ${ }^{52}$ For Radin, this requirement formed the first of two basic principles of the Rule of Law. ${ }^{53}$ Dicey's Rule of Law also reflects the requirement that there be rules and that they be in general terms applicable to all. ${ }^{54}$ Whilst both striking and interesting, mere similarity of expression achieves and reveals little; this represents only the commonality of desiderata referred to in the previous part. Comprehension - as a requirement that an individual be able to comprehend the nature, content and operation of the rules to which he or she is subject-is

\footnotetext{
${ }^{44}$ Raz (n 8) 214-5; Fuller (n 12) 63.

${ }^{45}$ Fuller (n 12) 81.

46 ibid 65 .

${ }_{47}$ Regarding the requirement that rules be announced beforehand: ibid 49; Hayek, The Road to Serfdom (n 26) 112. Regarding the requirement that an individual have an awareness of the laws of the state in order to modify one's action: Friedrich A von Hayek, The Constitution of Liberty (University of Chicago Press 1960) 210; Solum (n 20) 122; Thomas Hobbes, Leviathan: With Selected Variants from the Latin Edition of 1668 (EM Curley ed, New Ed edition, Hackett Publishing Co, Inc 1994) ch 26.

${ }^{48}$ As the principle of 'Generality' See Fuller (n 12) 46.

${ }^{49} \operatorname{Raz}(\mathrm{n} 8) 213$ and 216.

50 Solum (n 20) 122.

${ }^{51}$ Hayek, The Road to Serfdom (n 26). See also Hayek, The Constitution of Liberty (n 47) 218-219.

${ }^{52}$ See for example, Aristotle, T Sinclair and Trevor J Saunders, The Politics (Penguin UK 1981) ch 8 and 16.

${ }^{53}$ Radin (n 11) 785.

${ }_{54}$ AV Dicey, Introduction to the Study of the Law of the Constitution (9th ed, Macmillan 1939) 202-203.
} 
also evidenced across these ideas related to generality as individuals must understand that rules properly made and expressed in general terms will undoubtedly apply to him or her. ${ }^{55}$

Predictability, stability and constancy are frequently included within canonical Rule of Law formulations. ${ }^{56}$ When considered in prima facie terms they simply represent one small bundle of virtues that, notwithstanding their frequent invocation, relate to one way of achieving a goal in a particular Rule of Law theory; this is akin to the sharpness of a saw or heaviness of an axe. The reflection of the Fundamental Need in these desiderata becomes apparent when we conceive the desiderata as requiring an individual to know the rules he or she is subject to in advance, and to expect they will remain in force in the form in which they currently exist. Both relate to the parties' background understanding and beliefs. In this way, these desiderata are of similar effect to the common desideratum that stipulates the necessity for prospective laws and rules. ${ }^{57}$ These desiderata are individually and collectively aimed at ensuring parties are put in a position to know, understand and trust the continued operation of the rules and are able to predict, with some degree of certainty and confidence, the rules that will result in the imposition of sanctions. Raz puts it this way:

The violation of the rule of law can take two forms. It may lead to uncertainty or it may lead to frustrated and disappointed expectations. It leads to the first when the law does not enable people to foresee future developments or to form definite expectations... ${ }^{s s}$

The internal processing of information by (and the external transmission to) a party are represented by the need described by Radin and Fuller in relation to

\footnotetext{
${ }^{55}$ See Jeremy Waldron, 'Principles of Legislation' in Richard W Bauman and Tsvi Kahana (eds), The Least Examined Branch: The Role of Legislatures in the Constitutional State (Cambridge University Press 2006) 21.

${ }^{56}$ See for example, Aristotle, Sinclair and Saunders (n 52); Raz (n 8) 215; John Locke, Two Treatises of Government (Peter Laslett ed, Student edition., Cambridge University Press 1988) 350-352; Fuller (n 12) 79; Hayek, The Road to Serfdom (n 26) 114; Hayek, The Constitution of Liberty (n 47) 210. However, Hayek's views in relation to the operation, but not the necessity, of predictability later changed: Friedrich A von Hayek, Law, Legislation and Liberty: A New Statement of the Liberal Principles of Justice and Political Economy (1973) 115-118.

${ }^{57}$ See for example, Fuller (n 12) 51; Raz (n 8) 215; Hayek, The Road to Serfdom (n 26) 112; Locke (n 56) 353; Hayek, The Constitution of Liberty (n 47) 210.

${ }^{58} \operatorname{Raz}$ (n 8) 221-222.
} 
knowable desiderata. For Radin, the requirement of 'knowability' included the requirements that rules be public, congruent, non-contradictory, clear and relatively stable ${ }^{59}$ Fuller too prefaces various aspects of his Rule of Law conception with a necessary requirement for knowledge:

This lies in a quality shared by both, namely, that they act by known rule. The internal morality of the law demands that there be rules, that they be made known, and that they be observed in practice by those charged with their administration. These demands may seem ethically neutral so far as the external aims of law are concerned. Yet, just as law is a precondition for good law, so acting by known rule is a precondition for any meaningful appraisal of the justice of law. "A lawless unlimited power" expressing itself solely in unpredictable and patternless interventions in human affairs could be said to be unjust only in the sense that it does not act by known rule. ${ }^{60}$

Radin also considers the 'perform-ability' of desiderata as being in a separate, albeit related, category to know-ability. ${ }^{61}$ This approach is not incorporated-save by implication-into the concept of Comprehension. Explicit inclusion of any impossibility desideratum within Comprehension is not required. The idea that a law or rule is required to be capable of performance could be associated with a party's Comprehension only in terms where the party is capable of compliance in any event: a law that requires the impossible would be no law. ${ }^{62}$ In these terms, Comprehension (in broad terms) also incorporates - in addition to the purposive intent included in the other desiderata outlined above - the requirement that a law must be performable or, at least, not impossible.

\subsection{Procedural Pellucidity as an Element of the Rule of Law}

The second Rule of Law element-Procedural Pellucidity—requires the creation and application of any rules to be in terms capable of being clear and obvious to all concerned. In this regard, the process must be transparent and clear, affected in a careful and determined way following a process of evaluation, and the resulting

\footnotetext{
${ }^{59}$ Radin (n 11) 786.

${ }^{60}$ Fuller (n 12) 157. (Emphasis added.)

${ }^{61}$ Radin (n 11) 786.

${ }^{62}$ Fuller (n 12) 70.
} 
norms and decisions must be expressed clearly by the decision maker (as the norm creator or applier). As Jeremy Waldron has recently been the most outspoken and visible advocate for the inclusion of procedural aspects into the Rule of Law, and as his statements closely relate to Procedural Pellucidity, I explore his work in some detail in this section.

I begin, however, with some boundary setting. In reflecting the Fundamental Need behind the various canonical conceptions of the Rule of Law, Procedural Pellucidity has two prongs. Any decision or decision-maker must clearly and apparently demonstrate both. These prongs require that, first, a decision-maker consider various issues and, second, there be clear communication of the resultant decision. Procedural Pellucidity may apply to any rule-maker or decision-maker (whether a judge, legislator or any other power wielding decision-making agent of the government). ${ }^{63}$ A further instance of boundary setting is also required. The definition of Procedural Pellucidity, suggests an overlap between the second prong of Procedural Pellucidity - that there be clear communication of a decision-and the aspect of Comprehension that requires an individual to be able to comprehend the nature, content and operation of the rules. Although the overlap is not fatal-or even problematic in the terms of this assessment or the formulation of the elemental scheme generally - in the hope that the existence of Procedural Pellucidity can initially be considered on its own merits, I defer discussion of the overlap until Part IV.

The first prong - that a decision-maker consider various issues-is apparent across canonical conceptions. Whilst procedural values have recently gained wide acceptance following the inclusion-either directly or by implication — of procedural components in conceptions by, inter alia, Lon Fuller, Joseph Raz and Jeremy Waldron, ${ }^{64}$ the concept is not new. Aristotle, by way of decrying the making of hasty and emotion-fueled decisions, refers to the requirement for the inclusion of some form of (what would now be deemed) legislative due process. ${ }^{65}$ Whilst care should be taken in interpreting Aristotle's comments in the modern Western tradition, it is

\footnotetext{
${ }^{63}$ This is not to rule out the potential operation of the Rule of Law in private law. See Austin and Klimchuk (n 9) 1.

${ }^{64} \mathrm{n} 73$ below and accompanying text. See also, Raz (n 8) 214-217.

${ }^{65}$ Aristotle, Rhetoric (W Rhys Roberts tr, Dover 2004) bk 1 ch 1.
} 
apparent there is some call for a level of 'cool headedness' and the avoidance of impassioned decision making. Dicey famously propounded a similar due process requirement through the sentiment that "no man is punishable or can lawfully be made to suffer in body or goods except for a distinct breach of law established in the ordinary legal manner before the ordinary Courts of the land'. ${ }^{66}$ Whilst this view has not escaped criticism, ${ }^{67}$ and although his insistence on the Courts alone as an enforcement mechanism may have been shortsighted, it is apparent the conception is formal ${ }^{68}$ and the broad aim is clearly procedural.

Ronald Cass concludes that ' $[\mathrm{a}]$ dherence to the rule of law slows down changes in the system, increases the foreseeability of change, makes change less the product of one individual's will than of the more regularized and intricate interweaving of different wills and priorities.' 69 Cass Sunstein also imports a similar requirement together with requirements for: the separation of law-making and adjudicative processes and minimal due process requirements; hearing rights and availability of review by independent adjudicative officials; a separation between law-making and law-implementation; and the prevention of rapid changes in laws' content. ${ }^{70}$ Raz's laundry list of desiderata echoes this common procedural function by requiring that the making of laws be guided by clear and transparent rules and that natural justice is to be observed within courts that are easily accessible. ${ }^{71}$ Waldron, following a consideration of the Diceyean approach, concludes that of ' $\left[\mathrm{t}^{\mathrm{t}}\right]$ he legislature, the judiciary, and the executive--each must have its separate say before power impacts on the individual.'72 He also identifies procedural elements in the work of Raz and Dicey and a procedural component to the work of E. P. Thompson. ${ }^{73}$ Fuller's

\footnotetext{
${ }^{66}$ Dicey (n 54) 110.

${ }^{67}$ See for example, Kenneth Culp Davis, Discretionary Justice: A Preliminary Inquiry. (University of Illinois Press 1969) 35.

${ }^{68}$ Craig (n 7) 470. (Here, 'formal' is used in a sense opposite to substantial and not in the more limited sense as relating solely to the way in which a law is made. )

${ }^{69}$ Ronald A Cass, 'Property Rights Systems and the Rule of Law' in Enrico Colombatto (ed), The Elgar Companion to the Economics of Property Rights (Elgar 2004) 226.

${ }^{70}$ Cass R Sunstein, 'Rules and Rulelessness, (Program in Law \& Economics Working Paper No. 27 )' 15.

${ }^{71} \operatorname{Raz}(\mathrm{n} 8)$ 214-217.

72 Jeremy J Waldron, 'Separation of Powers in Thought and Practice' [2013] Boston College Law Review 433, 459.

73 Jeremy Waldron, 'The Rule of Law and the Importance of Procedure' in James E Fleming (ed), Getting to the rule of law (New York University Press 2011) 10.
} 
conception, Waldron suggests, 'has to do with legislative form, not judicial procedure...'74 and, augmentation of Fuller's desiderata with a further extensive set of procedural requirements is necessary else we 'radically sell short the idea of the Rule of Law'. ${ }^{75}$ Waldron advocates procedural ideas - legislative and judicial —in his own work. In relation to legislative law making, he suggests a list of procedural principles of legislation that require, inter alia, disagreement must be allowed, a forum must give voice and general consideration to issues raised, deliberation and debate be engaged in and due care must be taken. ${ }^{76}$ The distinction here appears to be one between formal in a narrow sense (relating only to the rules regarding making a law) and the process of applying the law; Waldron accords procedure only the narrow interpretation. (Although procedural is conceived of in a slightly broader context in the present investigation, there seems to be little that ultimately turns on this differentiation.) One reading of Waldron's desiderata could be restricted to the operation of a hearing before some form of tribunal. On this-more restrictiveinterpretation, the desiderata largely reflect a list of due process requirements. This appears to be conceded in a later passage where he states ' $[\mathrm{t}]$ he point is that there is very little about due process or courtroom procedure in Fuller's account of law's internal morality...' ${ }^{77}$ The other desiderata suggested by Waldron, also largely relate to the narrowly defined requirements of due process. ${ }^{78}$ In this respect, it is no surprise that Waldron's conception of procedure is narrower than that representing the Fundamental Need encompassed by Procedural Pellucidity. Waldron has also suggested a wider interpretation. It is not enough, he says, to simply state 'plaintiff wins', as satisfaction of the Rule of Law may require articulation of exactly why that party has won; and this could extend to the existence of a right to reasons for a decision. ${ }^{79}$ These aspects are reflected in Procedural Pellucidity as satisfaction requires there to be clear communication of reasons for any decision and that there must be

\footnotetext{
74 ibid 9.

75 ibid $6-7$

${ }^{76}$ Waldron, 'Principles of Legislation' (n 55) 18.

77 Waldron, 'The Rule of Law and the Importance of Procedure' (n 73 ) 8.

78 ibid. (These include: rights to a hearing before a trained judicial officer; to legal representation; to present evidence and arguments; to confront witnesses; and, to be present at critical stages of the proceeding.)

79 ibid; Jeremy Waldron, 'Stare Decisis and the Rule of Law: A Layered Approach’ 17.
} 
consideration of the arguments presented. Where the idea of procedure is being applied to the wider process of law making-relating to the contact of all wings of the Government referred to by both Dicey and Waldron ${ }^{80}$ - it is not anticipated that the meaning and description of 'procedural' will be stretching the concept too far. Each of these ideas of the Rule of Law suggest a commonality of purpose that requires there to be careful, and obvious, consideration of decisions during decision-making or in affecting rules. These are reflected in the first prong of Procedural Pellucidity.

The second aspect - that there be communication of any decision-can be very briefly stated. This is both explicitly part of the various procedural conceptions already noted as well as a necessary implication in circumstances where, as has already been demonstrated, there is a frequently stated requirement for the Rule of Law to be promulgated. ${ }^{81}$

As will be apparent from the exploration of these procedural ideas of the Rule of Law, there is a requirement that there be clarity in both processes of evaluation and determination and in the expression of those norms. This brief review suggests Procedural Pellucidity as a reflection of the Fundamental Need - that the creation and application of any rules must be in terms capable of being clear and obvious to all concerned-is held in common across and can be inferred from the various canonical conceptions of the Rule of Law.

\section{Part IV: Elements of the Rule of LaW: Summary and Objections}

Through their ready identification within—or at least behind — the canonical conceptions referred to above, Comprehension and Procedural Pellucidity are elements of the Rule of Law that - given the theoretically agnostic process of distillation and their reflection of the Fundamental Need expressed in canonical conceptions - provide a way to assess Rule of Law non-compliance regardless of the canonical conception preferred. Where Comprehension and Procedural Pellucidity (respectively) require an individual to be able to comprehend the nature, content and operation of the rules to which he or she is subject and, require the creation and ap-

\footnotetext{
${ }^{80} \mathrm{n} 66$ and 72 above.

${ }^{81} \mathrm{n} 47$ above and associated text.
} 
plication of any rules to be in terms capable of being clear and obvious to all concerned, it is apparent that both processes and outcome are critical to Rule of Law compliance. By way of a quick 'sense check', this does not immediately contradict popular or intuitive ideas of what the Rule of Law is. The elements provide a pragmatic solution to the problems highlighted at the start of this paper. They enable identification of whether a rule-maker's actions or a rule as made are capable of complying with any one of a variety of canonical Rule of Law conceptions without having recourse to each conception individually, having to select a hybrid model or having to formulate a novel Rule of Law conception. Furthermore, given the way in which the elements have been identified — as a reflection of the commonly held Fundamental Need across canonical conceptions - they exist beyond the concept's current state of contestedness. I have no doubt that questions or objections exist. Accordingly, I attempt to preempt some objections, by posing and briefly answering five questions.

\subsection{Can the Elements Unify the Conceptions/Remedy the Contestedness?}

Given the contestedness of the Rule of Law-and if it is correct that the Rule of Law is, as is widely accepted to be the case, an essentially contested conceptwouldn't the existence of any element (as defined herein) be a misnomer and an irrelevance as there can be no such unifying principle between conceptions? ${ }^{82}$ Should it be asserted that Comprehension and Procedural Pellucidity operate as a direct bridge between various conceptions this objection could not be denied. However, that is not the claim. Should that be the claim, it would be like stating an axe is actually a saw. Or, more specifically, like stating that an axe can be conceived of as being conceptually and fundamentally a saw simply by virtue of the purpose to which the tool is being put. Care has been taken to avoid that position. The elements proposed reflect a common Fundamental Need. This need does not bridge between conceptions - or even the contest between them-but, instead, looks to the purposive intent behind the conceptions. The connection is one of purpose alone; as the purpose is the Fundamental Need that the canonical author seeks to address by

\footnotetext{
82 This question could be considered as making a straw man out of Gallie's idea of essential contestability. (I thank the anonymous reviewer for highlighting this position.) I do not take issue with that suggestion. However, I retain the question as an objection as it usefully highlights the operation of the elemental scheme as the objection could also be raised absent essential contestability.
} 
providing his/her Rule of Law conception as a solution to a problem. In terms of the axe/saw analogy, these are tools useful in the act of cutting down a tree. This is not to suggest these are the sole uses for either tool or that they are the only tool for the job; after all, a saw can also be used for cutting timber or as a musical instrument and an axe can be utilised as a weapon of war or be used-perhaps, by either a fire fighter or Jack Nicholson's character in the Shining-to gain access to a locked room. For these reasons, the Fundamental Need does not suggest the elements provide a unifying theory of the Rule of Law. In fact, the suggestion is precisely that the elements - by simply indicating commonality of purpose - avoid having to determine or state these things. Further, as the elements exist at a state of abstraction removed from the plane on which the contest currently takes place, the contest - whether properly characterised as being essentially contested or not—cannot directly be solved through the proposed methodology. As already noted, I aim only to solve the problems outlined at the start of this paper by going beyond the contest iteself.

\subsection{Does the Overlap Between the Elements Result in a Problem?}

The cohabitation of the same conceptual terrain by the two elements does not represent a conflict in the true sense of the word, as the elements' operation is not exclusive. As alluded to already, both processes and outcomes are crucial to Rule of Law compliance. The two elements exist on a single spectrum flowing between processes and outcomes. Procedural Pellucidity is exclusively situated at the processes end of the spectrum as a consequence of its role in the making of norms; Comprehension exclusively occupies the outcomes end of the spectrum as a result of its relation to the internal processing of information (provided by the norms). In the middle, is the 'overlap' where there is a dual concern between the elements regarding the expression or communication of norms. This 'overlap', however, does not result in a mixing of the elements' function. The two elements relate to different sources: Procedural Pellucidity to norm-makers and appliers; and Comprehension to norm-followers. It is due to this exclusivity of source application that the two elements cannot, and should not, be collapsed together.

What would it mean if an action facilitates Comprehension but not Procedural Pellucidity (or vice versa)? The answer is deceptively straightforward: non- 
satisfaction of either one of the elements means Rule of Law compliance does not follow. This result obtains as both elements are necessary (but not sufficient) elements of the Rule of Law conceptions. Although a small area of 'overlap' may exist, neither element covers the entire field. An action that supports only one element would leave a substantial necessary area of the Rule of Law unsatisfied. It is only together that the elements facilitate Rule of Law compliance; non-satisfaction of either element is sufficient to result in Rule of Law non-compliance.

\subsection{Why not Abstract Further? ?ss $^{\text {S }}$}

Further abstraction is, of course, possible. However, in considering two instances of further abstraction, abstracting beyond the Fundamental Need results in a loss of pragmatic benefits or practical application of the elemental scheme. In other words, altering the level of abstraction-in either direction from the Fundamental Need-can result in a less desirable solution to the problems outlines at the start of this paper. In this respect, the line in the sand drawn by the elements I propose represents an attempt to achieve the maximum pragmatic benefit.

The first instance of further abstraction beyond the Fundamental Need has already been mentioned above. This would - in tool related terms-suggest the purpose to be inferred from the use of an axe is firewood or heat, and not merely cutting down a tree. To accurately abstract to each canonical author's specific goal would require a complete appreciation of the precise intentions and motivations resulting in the formulation of the Rule of Law conception. Even if an exhaustive study of each canonical author were undertaken, the result would remain speculative. The less abstract the inference-and the closer to the conception communicated in the canons - the less speculation is required. In addition, as each author's ultimate aim may have differed slightly as a result of each conceiving of the problem in slightly different terms, it seems likely that a divergence in those goals would occur when further abstraction is considered. Accordingly, consideration of the more abstract goal makes convergence and commonality of purpose less likely to be achieved or identified. For these reasons, attempts to divine a more abstract purpose appears to be both impractical and fruitless.

\footnotetext{
${ }^{83}$ I thank Claudio Michelon of the University of Edinburgh for posing this question following a general discussion of my methodology.
} 
There is a second, and different, instance of abstraction. Couching a general conception of the elemental content of the Rule of Law in more abstract terms is possible via recourse to the, largely uncontroversial, overly broad idea of the Rule of Law referred to at the start of this paper: that the Rule of Law is nothing more than some level of normative force that acts on a rule-maker in a way that, ultimately, prevents the exercise of arbitrary power. At some stage along the continuum of abstraction toward this 'ultimate' position, the act of abstraction itself becomes pointless; the level of abstraction results in the idea becoming, in practical terms, devoid of meaning. Of course, the same result obtains in the opposite circumstance: abstracting less results in the non-avoidance of the instant issue of contestedness and, hence, the assessment would provide no benefit. For all of these reasons, a line in the sand is required. The intention behind the line-placement suggested by the elemental conception proposed herein seeks to bisect the problems raised by the titular questions posed below-Are there pragmatic benefits? and, Why not use another conception?-and the concept's general maelstrom of contestedness.

\subsection{Are there any Real Pragmatic Benefits?}

I provide two brief examples to illustrate the elements - though abstract- do still provide pragmatic benefits. The elements are necessarily more abstract than the conceptions from which they are distilled, but they are not so broad as to be irreconcilable with any Rule of Law-relevant example.

There is little doubt that aspects of the Nazi regime would not pass the elemental Rule of Law muster. In considering the Roehm Purge ${ }^{84}$ it is clear there would be a complete failure of Procedural Pellucidity. This means the events and actions could not be said to satisfy the Rule of Law in any canonical conception. However, this extreme example alone provides little benefit regarding the location of the metaphorical line in the sand. If the elemental scheme is to have any value it must at least have some potential in determining, or, at least, not excluding, the 'hard' cases. A second example that is intuitively (potentially) more ambiguous will assist. An Australian Prime Minister announced the next sitting parliament would

\footnotetext{
84 The Roehm Purge occurred when Hitler ordered, and retroactively authorised, mass murders before stating that the court of Germany had consisted of himself. See Lon L Fuller, 'Positivism and Fidelity to Law: A Reply to Professor Hart' (1958) 71 Harvard Law Review 630, 650.
} 
retrospectively criminalise a particular act from the date of the announcement. ${ }^{85}$ The making of the announcement arguably — in some conceptions of the Rule of Law - may negate the retrospectivity that would ordinarily be fatal (in criminal matters). Of the various conceptions that vehemently oppose retrospectivity, Fuller's is one of the best known: 'Taken by itself, and in abstraction from its possible function in a system of laws that are largely prospective, a retroactive law is truly a monstrosity.' ${ }^{86}$ Although space does not afford opportunity to provide a detailed examination regarding the elements, a cursory consideration suggests two considerations of note. First, the Prime Minister's announcement may be able to obviate invalidity due to retrospectivity as Comprehension may be facilitated through the manner, nature and content of the announcement (notwithstanding the specific legislative steps necessary to criminalise an act). ${ }^{87}$ Procedural Pellucidity would substantially be satisfied on the passing of the Act in the normal course of parliamentary procedures. But, it seems, there would be no Rule of Law compliance at the point of the announcement; compliance may only achieved through the two acts separated in time. However, and this is the second point, it is not immediately apparent there is a slam-dunk answer as there remains some wiggle room in relation to the application and precise terms of the internal and external operation of Comprehension in the given example.

These examples - in circumstances where the elemental scheme is intended only to operate as a shorthand way to identify Rule of Law non-compliance-suggest the line in the sand is in a position that retains some analytic value and does not create a category that is either too broad to be devoid of purpose or too narrow so as to exclude any potential application. However, where satisfaction of Comprehension and Procedural Pellucidity would not guarantee ultimate Rule of Law compliancethere may be other reasons that impact that outcome - the elemental scheme can be seen to be doing some work in two senses: first, it disposes of the relatively clear

\footnotetext{
85 This example has previously been applied by Waldron. See Jeremy Waldron, 'Retroactive Law: How Dodgy Was Duynhoven?' (2004) 10 Otago Law Review 631, 634-636. The act in question related to the making of hoax threats of Anthrax having been posted to institutions. Although Waldron uses the example to differentiate retroactive and retrospective legislation, the illustration works equally well here. ${ }^{86}$ Fuller (n 12) 53.

${ }^{87}$ Putting aside the obvious issue that the mere words of a Prime Minister are not constitutive of a legally binding norm.
} 
Nazi example; and second, it leaves open the somewhat ambiguous example for further examination. On this basis, the line in the sand appears to be in broadly the right place for the immediate identification of non-compliance. In other words, the scheme is able to provide the pragmatic benefit of being able to rapidly and easily determine an instance of non-compliance without having recourse to all canonical conceptions separately. The theoretical agnosticism inherent in this approach results in the ability to draw a more robust conclusion to any analysis.

\subsection{Why not use an Existing Conception?}

The immediate response to this question harks back to the issues posed earlier in the paper: in terms where the content of the Rule of Law is not settled, adoption of a single or hybrid methodology is open to immediate criticism. However, the question could also relate to the criticism of the use of the elemental scheme in a way that supplants existing canonical Rule of Law conceptions. Should this be the thrust of the question, the response is that there does still remain a need to use the existing canonical conceptions. I am not suggesting the elemental conception supplants, replaces or is superior to those conceptions. Indeed, that cannot be the case where the elements - as necessary and not sufficient aspects of the Rule of Law - are limited to identifying only non-compliance. So, on this basis, it will still ultimately be necessary to have recourse to other, existing, conceptions if non-compliance is not established.

\section{PART V: CONCLUSION}

I have argued two elements of the Rule of Law can be distilled from canonical Rule of Law conceptions and that these provide a theory agnostic way to establish Rule of Law non-compliance. The Fundamental Need behind Rule of Law canonical conceptions represents commonality of thinkers' purpose and this commonality is reflected in the elements. The two necessary Rule of Law elements (although there may be more) can be used to identify non-compliance with the Rule of Law in a way that satisfies all canonical conceptions. This approach avoids the problems and criticisms associated with the adoption of part or all of one or many 
canonical conceptions or the logistical impracticability associated with the generation of a bespoke complete Rule of Law theory. In this way, the elemental approach facilitates a robust and practical methodology for identifying Rule of Law non-compliance. 